\title{
CMA Exam Review Courses
}

\author{
Doug Barney \\ Indiana University Southeast \\ Daniel Tschopp (Corresponding Author) \\ Saint Leo University \\ Email: tschopp2@buffalo.edu \\ Steve Wells \\ Western Kentucky University
}

Received: February 22, 2012 Accepted: April 22, 2012 DOI: 10.5296/ijafr.v2i1.1562

\begin{abstract}
The National Association of Accountants, later renamed the Institute of Management Accountants (IMA), started the Certified Management Accountant (CMA) certification program in 1972. Since then the number of candidates seeking the CMA certification has grown, most notably in the last several years. This growth is fueled by several factors, including:

- The IMA has expanded the base of prospective candidates by easing the international application process.

- Surveys repeatedly show that CMAs earn significantly more than their counterparts without CMAs, thus enticing more accountants to seek the CMA certification.

- The redesigned CMA exam identifies and tests competence on practical business topics, thus emphasizing the applicability of CMA knowledge.

- Recognition and acceptance of the CMA by the business community has grown dramatically in the last 40 years.
\end{abstract}

CMA candidates have a number of exam preparation options, including several CMA review course providers. (called Providers hereafter in this article.) This article is intended to be informative for those individuals seeking the CMA certification and wishing to prepare for the exam with a review course. With the change in CMA exam format, a reexamination of Providers is certainly relevant, especially in light of the approaching 40 year anniversary of the CMA.

Keywords: CMA Exams, certification, Institute of Management Accountants (IMA) 


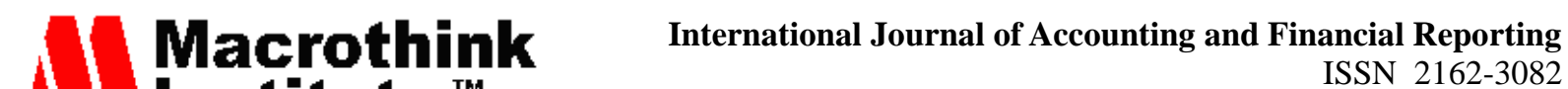 2012, Vol. 2, No. 1}

\section{The New CMA Exam Format}

The IMA designed the CMA exam on a four part basis years ago. As of January 2011, however, the exam has two parts. Some CMA candidates are grandfathered in under the old four part exam, but for all those applying to sit for the CMA now, the exam has two parts. All the Providers provide material under the new two part exam.

The CMA exam is designed to measure the advanced skills required to be an effective member of finance and accounting teams within organizations and to create value in today's complex and challenging business environment. The exam is structured as follows:

PART I - Financial Planning, Performance and Control

- Planning, budgeting, and forecasting

- Performance management

- Cost management

- Internal controls

- Professional ethics

PART II - Financial Decision Making

- Financial statement analysis

- Corporate finance

- Decision analysis and risk management

- Investment decisions

- Professional ethics

http://imanet.org/cma_certification/about_the_cma.aspx

Candidates can take the exam in three separate two month windows at Prometric learning centers. On each part of the exam candidates have 4 hours to answer 100 multiple choice and 2 essay questions. Besides successful completion of the CMA exam, licensure requires completion of a four year college degree (in any discipline) and two years of relevant work experience. If you are considering pursuing the CMA designation, check the IMA website (at imanet.org) for more detailed information.

\section{CMA Review Course Providers}

There are currently seven organizations providing CMA review materials. These materials include a variety of formats such as live or videotaped lecture, texts, question and answer books, online questions, and flashcards. The tables provide an overview of the organizations and their approach to the CMA review. There are some factors common to most or all Providers: 
- Websites are easy to navigate;

- Websites provide testimonials as to why you should rely on their products;

- Guarantees are common, but generally require strict adherence to the planned study regimen and/or quick return time;

- Most online materials have a limited time access, usually one to two years;

- Providers offer exam study plan/guide to prepare for the CMA exam;

- Providers have practice exams as part of software study materials.

Following is a discussion of key characteristics of each Provider, listed alphabetically. The information comes from the companies' websites, promotional material, and responses to inquiries. Table 1 provides information about the providers and Table 2 provides information about the review packages the providers offer. This information is current as of this article publication date, but is subject to change.

\section{Exam Matrix}

Exam Matrix entered the examination review business 2003. The company now provides a number of review courses including CMA, CPA, CIA, CISA (Certified Information Systems Auditor), and Enrolled Agent exams. For the CMA exam, Exam Matrix provides 2,400 multiple choice questions and 36 essay questions on CD. The course also includes a text (hardcopy and on CD) covering the CMA material. Exam Matrix offers the text and cd for $\$ 545$.

According to the provider's website, Exam Matrix touts its 'Adaptive Learning' system as the method to use for passing the CMA exam. When exam candidates use this system, the multiple choice questions change or adapt based on the candidate's performance in any particular area, allowing the system to select more questions in study areas needing improvement. (Exam Matrix was not the only provider using this adaptive system.) This software system also generates reports identifying the text section the candidates should study for questions the candidate missed.

\section{Gleim}

Gleim has been in business for over 40 years and offers a multitude of support material for accounting (CMA, CPA, CIA, and Enrolled Agent) and aviation. Gleim offers numerous options for CMA exam review. Materials run the gamut from weekly live presentations by professors combined with a 'personal counselor' to help candidates design their study strategy to audio presentations candidates can review while they drive. Gleim also offers texts and test prep software downloads with exam questions and explanations candidates can study at their desks or at home. The price for the standard review package (Gleim CMA Review System) is $\$ 740$ or $\$ 425 /$ part, which includes pretty much everything except the professor-led live review interface and instructor. Candidates can opt to buy CMA review material in parts, including the test prep software only for $\$ 145$ per exam part. This software tracks candidate progress, so that candidates can identify study areas needing improvement. According to Gleim's website, "[t]he 'Performance Analysis' system tracks your progress and maintains a performance history so you can strengthen your weak areas." 


\section{Mll Macrothink}

International Journal of Accounting and Financial Reporting

ISSN 2162-3082

2012, Vol. 2, No. 1

Professor-led live reviews are also available at some schools. Contact Gleim for a list of locations and prices.

\section{HOCK International}

Brian Hock founded HOCK international in 2003, based on the training he conducts in Europe. HOCK International quickly expanded to provide training for several certification programs, including CMA and CIA. HOCK International provides texts, flashcards, recorded lectures, and 'thousands of questions sorted by topic.' The price for both hard copy and downloadable versions for both parts of the CMA exam is \$525. As part of the set candidates get a study plan (based on the time until they plan to sit) and online access to an advisor to answer questions about specific review questions. When a candidate buys the combined set, they also get a copy of HOCK International's 'Assumed Knowledge e-book,' which is available in downloadable form only. The 'Assumed Knowledge' book lays the foundation for understanding material that CMA review courses might normally assume a candidate already knows. HOCK also offers a discount (up to \$100) to any CMA candidate who purchased materials from another provider and was not satisfied with those materials.

\section{IMA Learning Center}

The IMA Learning Center started providing review materials in 2001. While the Learning Center is affiliated with IMA, all CMA review providers get access to the same information about the CMA exam. The IMA Learning Center provides online multiple choice and essay questions and answers and texts. There are several packages available for study, with the full package for both parts totaling $\$ 995$ for members or $\$ 1,210$ for non-members. IMA professional memberships are $\$ 195$ annually or $\$ 130$ for professionals under 33 years of age, so the discount makes it worthwhile to join IMA, which anyone (non-CMAs included) can do. Candidates can also purchase the study materials for each part individually for $\$ 595$ for members and $\$ 695$ for non-members. Candidates can contact (online) a 'subject matter expert' to answer specific questions about material.

\section{Lambers}

Lambers started as an educational provider in 1966 and currently provide review material for CPA, CMA, CFA, CIA, and EA exams. According to the Lambers' website, "[t]he Lambers staff gives as much attention to omission as inclusion of subject matter in each review. Topics are presented only if they are relevant to the exam." Lambers offers audio courses, $(1,000)$ flashcards and test prep software. Lambers design its software to adjust to your learning needs, focusing on your weak knowledge areas. Lambers do not use lists or mnemonics, Lambers will "teach you the concepts, so you are prepared to answer any question you might encounter on exam day."

Lambers offers a combination of audio, flash cards, and CDs for CMA Exam review. Candidates can purchase the complete set for $\$ 950$. 


\section{Al Macrothink}

\section{Rigos}

James Rigos started the 'Rigos School' in 1980 in Seattle with a CPA review course. In 1985 Rigos added the CMA Review course. Rigos discontinue edits live review courses but individuals can buy the CMA Review text and software for $\$ 180$. The software contains 1,200 multiple choice questions and answers.

\section{The Tutorial Group}

The Tutorial Group specializes in flashcards for CMA, CPA, CFP, and EA reviews. The complete set of 1,000 CMA Review flashcards is $\$ 250$ or $\$ 150$ per CMA exam part. For those CMA candidates who like flash cards for learning material, The Tutorial Group offering may be the right option.

\section{Conclusion}

Various websites give testimonials and forums for discussion of the Providers. Certainly quality of the review program should play a strong role in your purchase decision. While quality of the program may be hard to discern before you buy the product (and even after a candidate purchases a review program quality is quite subjective), two other factors these authors recommend you consider are cost and study style. There is a significant difference in costs of CMA review materials. Study style will determine whether you prefer reading texts, flashcards, online lectures, focusing on many multiple choice questions, or live forums. Some forms of study are more appropriate for those candidates who travel frequently, or who like to move around while they study, or like to hear the material instead of reading it. If you are a dedicated student, you may do well with just the texts at a lower cost. If you need more 'push' to study for the CMA exam, you may want to get some interactive or video study materials. You might want to see if there is a professor-led review course in your area. We have tried to make the information available for you to make an informed decision. Whatever your decision, adherence to a quality review course will help you prepare for the CMA exam. 